\begin{tabular}{|l|l|l|l|l|}
\hline Crystal Res. \& Technol. & $\mathbf{1 9}$ & 1984 & 8 & $1073-1078$ \\
\hline
\end{tabular}

P. Rudolph, P. Grlef, Ch. Genzel, T. Boeck

Humboldt-Universität zu Berlin, Sektion Physik, Bereich Kristallographie

\title{
Investigations of the Process of Crystal Growth from a Liquid Zone by Seebeck Measurements
}

\begin{abstract}
An arrangement for measuring the thermoelectric voltage (Seebeck signal) during the crystal growth from a liquid zone is described. Using the example of growing PbTe single crystals by THM it is shown that different equilibrium temperatures at both phase boundaries provide a differential Seebeck voltage depending on the crystal growth rate. Relaxation times which are needed to reach steady-state conditions with respect to the concentration difference between the growing and solving interface in the case of a start or sudden stop of the heater motion can be obtained.
\end{abstract}

Представлен способ измерения термоэлектрического напряжения (сигнала Зеебека) во время пропесса кристаллизации зонной плавки. На примере выращивания РbТе методом движущегося нагревателя показано, что вследствие неодинаковых температур равновесия на обоих фазовых границах возникает дифференциальный сигнал Зеебека, величина которого зависит от скорости њристаллизации. Возможно исследовать время релаксации после старта и торможения движения зонного нагревателя, необходимое для создания и выравнивания концентрационной разницы между обоими фазовыми границами.

\section{Introduction}

Crystal growth from solution has proved particularly interesting with regard to materials being subject to dissociation and showing a low critical shear stress at temperatures near the melting point and a strongly retrograde course of the solidus line. $\mathrm{PbTe}$ which is a basic material for infrared devices is considered such a substance. Among different solution growth techniques, THM from a Te-rich solution zone at temperatures higher than $405{ }^{\circ} \mathrm{C}$ (eutectic temperature) is the most promising method for growing PbTe single crystals. (TRIboulet et al.; Gille, Rudolph).

The THM principle is to be seen from Figure 1. There is only little difference in comparison with the conventional zone melting procedure. Nevertheless, because of the mainly diffusion-defined transport within the solution zone, usual THM growth rates are lower than those with zone melting by one or two orders of magnitude. Reviews have been given by Wolff, Mlavsky; Benz, Bauser. Several materials could be grown by this method.

\section{Transport problem in THM}

The main difference between THM and zone melting with respect to the crystal growth process is to be seen from Figure 2. The travelling heater moves to the solution zone relatively, creating different liquidus temperatures $T_{2}$ and $T_{1}$ at the solving (2) and the growing interface (1), respectively. As a consequence the remarkable difference 


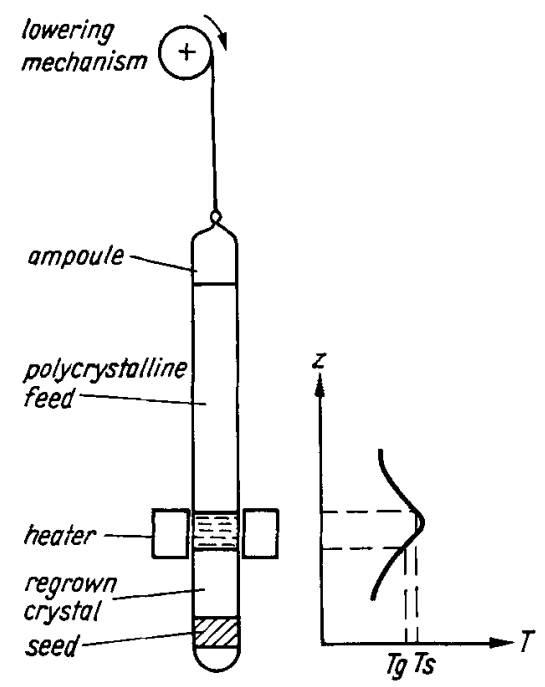

Fig. 1. Schematic representation of the THM principle $\left(T_{\mathrm{g}}, T_{\mathrm{g}}\right.$ - temperatures at the growing and solving interfaces, respectively)
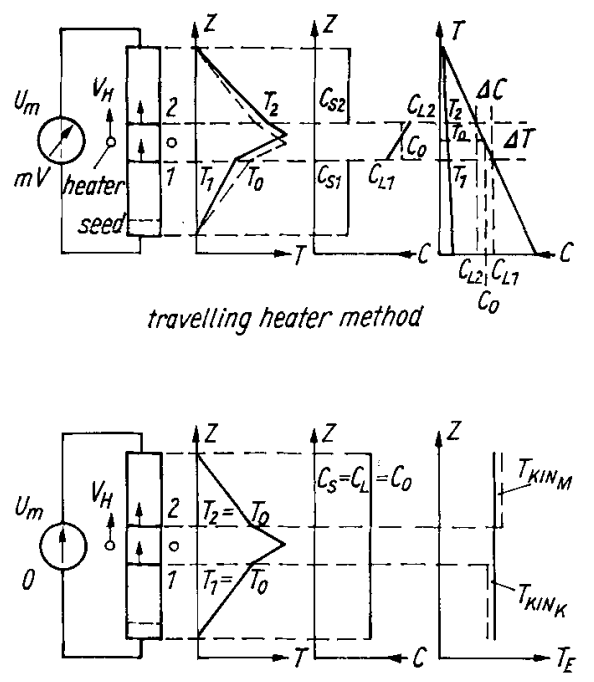

conventional zone melting

Fig. 2. Comparison between THM and zone melting $(1-$ growing interface, 2 - solving interface, $v_{\mathrm{H}}$ - heater velocity, $U_{\mathrm{m}}$ - Seebeck voltage, $T$ - temperature, $c$ - solute concentration in the solid (S) and in the liquid (L), $T_{E}$ - temperature of the crystal melt equilibrium, $T_{\text {kin }}$ - kinetic interface temperature, $z$ - distance)

in temperature $\Lambda T$ between the two phase boundaries leads to a concentration difference $\Delta c$ between the corresponding values $c_{\mathrm{L}, 2}$ and $c_{\mathrm{L} 1}$, according to the liquidus line of the phase diagram. With diffusion as the only transport Mechanism to be considered this difference in temperature depends, among other things, on the heater velocity and is to be approximated by:

$$
\Delta T=m_{\mathrm{L}} v_{\mathrm{H}} l_{\mathrm{z}}\left(c_{\mathrm{s}}-c_{\mathrm{L} 1}\right) / D
$$

$\left(m_{\mathrm{L}}\right.$ slope of the liquidus line; $v_{\mathrm{H}}$ rate of heater travel; $l_{\mathrm{z}}$ zone length; $c_{\mathrm{S}}$ and $c_{\mathrm{L} 1}$ concentrations of solute at the growing interface in the solid and in the liquid, respectively). 
Unknown diffusion coefficients $D$ of $\mathrm{PbTe}$ in a liquid $\mathrm{PbTe}-\mathrm{Te}$ mixture at temperatures between $450{ }^{\circ} \mathrm{C}$ and $550^{\circ} \mathrm{C}$ complicate an estimation with regard to relation (1).

Contrary to THM, both phase boundaries in the conventional zone melting procedure are of the same temperature if interface kinetics are not regarded, as we do in this study. The knowledge of differences in temperature $\Delta T$ between the two interfaces in THM is one of the most important problems with respect to the theory of transport and to technical questions. This difference, itself depending on the heater velocity, offers the greatest possible growth rate. An exact calculation of this value requires the knowledge of diffusion coefficients (KARKLINA, KovaLČIK). A direct determination by measurements with thermocouples is impossible because of their influence on the system.

\section{Principle of measurements}

Completely new ways of ascertaining differences in temperature in THM arise from Seebeck measurements over the total length of the crystalline ingot during the THM growth run (RUDOLPH et al.), as schematically shown at the left-hand side of Figure 2. This is also true of zone melting, if kinetics should cause an essential potential.

We have constructed an arrangement to measure Seebeck signals during growing PbTe crystals from a Te-rich solution zone, which is to be seen from Figure 3 . The ingot involving the solution zone is held by a spring contact within an evacuated silica ampoule. The total voltage as well as compensated values can be obtained with an accuracy of $\pm 20 \mu \mathrm{V}$.

The measured Seebeck signal of the described arrangement is composed of the volume part of the crystalline materials and of the differences of both Seebeck contact voltages between the boundaries of the liquid zone. The volume part of the total Seebeck signal amounts to:

$$
U_{\mathrm{V}}=\int_{T_{\mathrm{K}}}^{T_{2}} \alpha_{\mathrm{S}}(T) d T+\int_{T_{2}}^{T_{\mathrm{K}}} \alpha_{\mathrm{F}}(T) d T
$$

( $\alpha$ Seebeck coefficient of the seed and regrown crystal $(S)$ and of the feed material $(F)$; $T_{1}$ and $T_{2}$ temperatures at the growing and solving interface, respectively; $T_{\mathrm{K}}$ temperatures at the contacts with the electric circuit, which for the purpose of this discussion are taken to be identical) The resulting Seebeck contact voltage runs to:

$$
\Delta U_{K 12}=\int_{T_{0}-\Delta T / 2}^{T_{0}+\Delta T / 2}\left[\alpha_{\mathrm{S}}(T)-\alpha_{\mathrm{L}}(T)\right] d T .
$$

$\alpha_{\mathbb{S}}(T)$ and $\alpha_{\mathrm{L}}(T)$ are the Seebeck coefficients of the solid (S) and liquid phase (L), respectively, at the phase boundaries having temperatures of $T_{1}=T_{0}-\Delta \mathrm{T} / 2$ and $T_{2}=T_{0}+\Delta T / 2$, i.e., the interfaces act as differential in-situ thermocouples.

Temperature-dependent Seebeck coefficients of most of the semiconducting materials are well known (GLAzov et al.). For PbTe it is pictured in Figure 4 and for comparison also for Ge and InSb. It is obvious that Seebeck coefficients of the liquid phase are usually negligible in comparison with those of the solid phase. For this reason:

$$
\Delta U_{K 12}=\int_{T_{0}-\Delta T / 2}^{T_{0}+\Delta T / 2} \alpha_{\mathrm{S}}(T) d T
$$

is a good approximation of the Seebeck contact voltage. The temperature-dependent course of the PbTe Seebeck coefficient $\alpha_{\mathrm{S}}(T)$ between the growth temperatures of $405^{\circ} \mathrm{C}$ and $550{ }^{\circ} \mathrm{C}$ may be expressed by

$$
\alpha_{\mathrm{s}}(T)=-0.633 \frac{\mu \mathrm{V}}{\mathrm{K}^{2}} \cdot T+301 \frac{\mu \mathrm{V}}{\mathrm{K}} .
$$




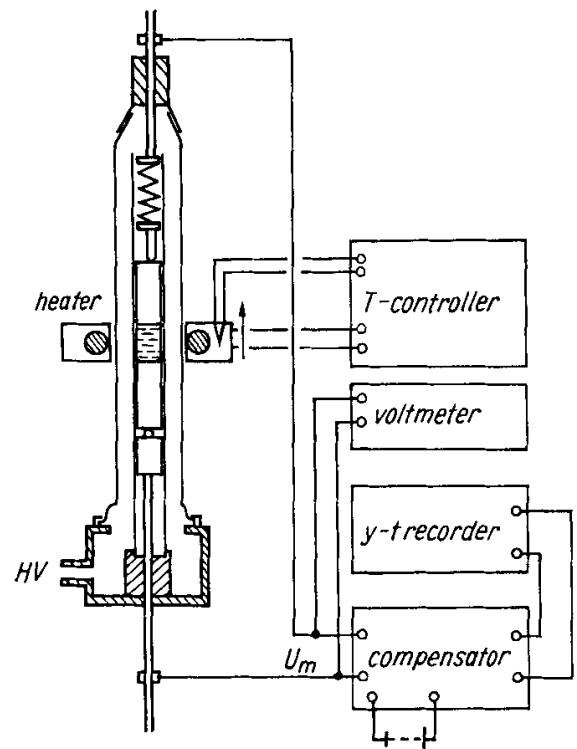

Fig. 3. Principle of measuring Seebeck voltages during THM growth (HV - high vacuum, $U_{\mathrm{m}}$ - Secbeck voltage)
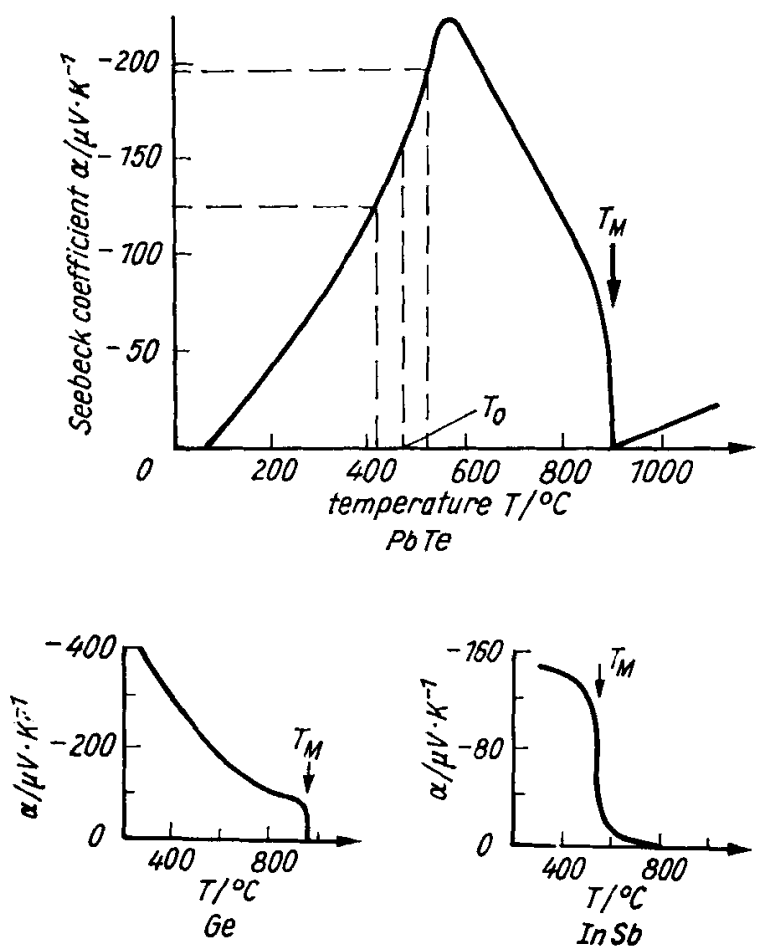

Fig. 4. Temperature dependence of Seebeck coefficients of some semiconducting materinls (GLAzov et al.) ( $T_{M}$ - melting point, $T_{0}$ - average solution zone temperature, dashed lines mark the temperature range used in THM) 
In this way a direct relation of the difference of Seebeck contact voltages between the two phase boundaries and the actual difference in temperature can be obtained. However, for the aim of separating the contact voltage the course of the volume part of the total Seebeck signal during a THM growth run must be known. For this reason we measured Seebeck voltages of a PbTe ingot under the usual THM growth conditions and with a moving heater but without a solution zone. Figure 5 shows the principle used. In the lower part the course of the voltage $U_{\mathrm{m}}$ measured over a $58 \mathrm{~mm}$ long $\mathrm{PbTe}$ rod with $12 \mathrm{~mm}$ in diameter in the temperature field of the THM experiments with continuously varying location of the heater relative to the ingot is pictured. In the central section there is an about $20 \mathrm{~mm}$ long linear course with a slope of $28.5 \mathrm{mV}$ per $\mathrm{cm}$ of the heater's travel, which allows the comparison with the experiments with zone.
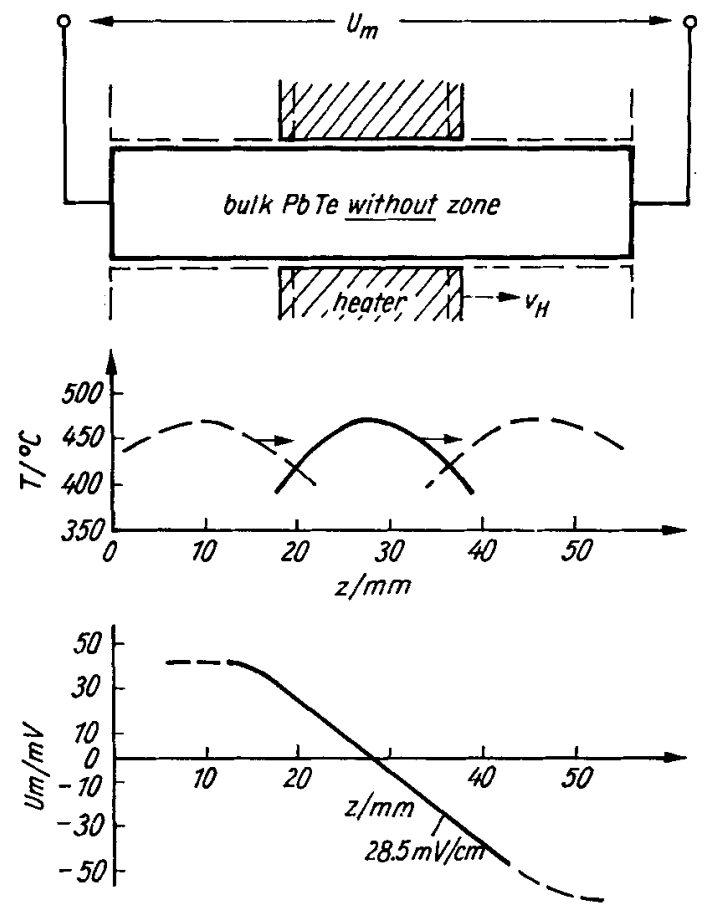

Fig. 5. Dependence of the volume part of the Seebeck voltage $\left(U_{m}\right)$ on the heater's location (z)

\section{First results}

From Figure 6 the time behaviour of the separated Seebeck contact voltage $A U_{\mathrm{m}}=$ $=\Delta U_{\mathrm{K} 12}$ with different heater velocities, i.e., with different rates of PbTe crystal growth from a $1 \mathrm{~cm}$ long Te-rich solution zone, can be seen.

After setting in motion the already hot heater (black arrow) the difference in temperature $A T_{12}$ between the phase boundaries increases until reaching steady-state conditions with the corresponding Seebeck voltage $\Delta U_{\mathrm{m}}$ according to the rate of heater travel. Comparable times are required to level the corresponding differences in temperature, concentration and Seebeck voltage between the interfaces in the case of a sudden stop of the heater motion without changing the heater's temperature (open arrow). This exponential relaxation behaviour gives evidence of diffusion processes within the liquid solution zone and may provide some information on material trans- 


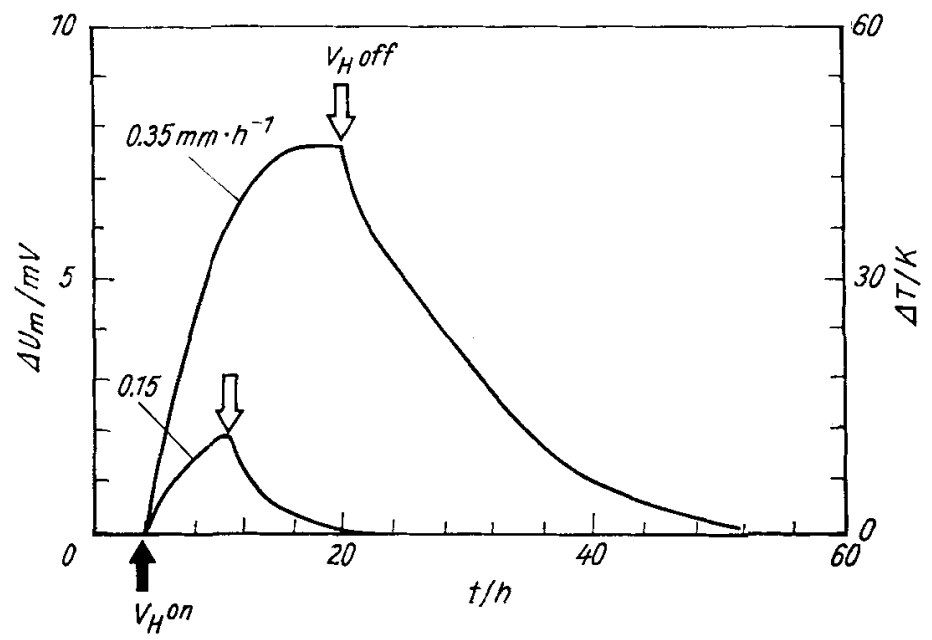

Fig. 6. Time $(t)$ behaviour of the differential Seebeck contact voltage $\left(\Delta U_{\mathrm{m}}\right)$ during THM growth of PbTe from a $1 \mathrm{~cm}$ long solution zone $\left(v_{\mathrm{H}}-\right.$ heater velocity)

port, if the travelling heater method is employed. Maxima of the functions represent Seebeck signals of steady-state conditions and can be transformed for the $\mathrm{Pb}$ Te system into differences in temperature between both interfaces by putting equation (3) in $(2 \mathrm{c})$ :

$$
\Delta T \simeq \frac{\Delta U_{\mathrm{m}}[\mathrm{mV}]}{-0.633 \cdot 10^{-3} \frac{\mathrm{mV}}{\mathrm{K}^{2}} \cdot T+0.301 \frac{\mathrm{mV}}{\mathrm{K}}}
$$

The measurement of Seebeck signals over the ingot during growing a crystal from a liquid zone has proved a suitable method of investigating the process of crystal growth. Further activities should be directed at revealing growth kinetics like rhythms of erystallization and using Seebeck voltages with the aim of an in-situ control in THM as well as in conventional zone melting.

The authors would like to thank Prof. Dr. habil. M. Schenk for helpful discussions.

\section{References}

Benz, K. W., Bauser, E.: in: Crystals. Growth, Properties and Applications, Vol. 3, pp. 8, Ed. by H. C. Freyhardt, Berlin, Heidelberg, New York 1980

Gille, P., Rudolph, P.: J. Cryst. Growth 64, 613 (1983)

Glazov, V. M., Cizevskaja, S. N., Glagoljeva, N. N.: Zidkie poluprovodniki, Moskva 1967

KarkLINA, M. T., Kovalčrı, T. L.: Isv. Akad. Nauk, Neorg. Mat. 4, 1344 (1968)

Rudolph, P., Girie, P., Boeck, T.: Wirtschaftspatent d. JDIR, Anmeld.-Nr. WP C 30 B/ $2543633(1983)$

Triboulet, R. et al.: Proc. 4th Int. Conf. on Phys. of Narrow Gap Semicond., Linz 1981 Wolff, G. A., Mlavskx, A. I. : in : Crystal Growth, Theory and Techniques, Vol. 1, pp. 193, Ed. by C. H. L. Goomman, London-New York 1974

(Received November 29, 1983)

\section{Authors' address}

Doz. 1)r. sc. P. Rudolph, P. Gille, Ch. Genzel, T. Boeck

Humboldt-Universität zu Berlin, Sektion Physik, Bereich Kristallographie

DDR-1040 Berlin

Invalidenstr. 43 